\title{
Pedagogía y manipulación en las columnas de opinión. Una experiencia desde el análisis crítico epistémico del discurso en la prensa colombiana
}

Recibido: 08 de septiembre de 2013

Aceptado: 31 de julio de 2014

Publicado: 28 de noviembre de 2014

\author{
Milton Vásquez Patiño \\ milton.vasquez@campusucc.edu.co
}

John Peña Tamayo

john.pena@campusucc.edu.co

Universidad Cooperativa de Colombia

\begin{abstract}
Resumen: El presente artículo expone una matriz de análisis crítico epistémico del discurso aplicada a la columna "Estado de opinión y clientelismo" de la articulista Alicia Eugenia Silva, publicada en el periódico El Tiempo, del sábado 30 de enero del 2010, durante en la etapa preelectoral para Congreso de la República en Colombia. El análisis de la columna identificó, en el discurso, los componentes pedagógicos y estrategias didácticas. Asimismo, permitió vislumbrar elementos textuales de manipulación que se dispusieron, con el fin de inducir al lector a tomar partido por los intereses de la columnista o de la propia casa periodística, activando, de esta forma, un intrincado proceso cognitivo entre autor y lector, donde gravitaron el lenguaje, la ideología, la comunicación de creencias y la interacción social.
\end{abstract}

Palabras clave: Pedagogía, política, manipulación, columnas de opinión.

Abstract: This paper presents an Epistemic Critical Discourse Analysis matrix applied to the column "Opinion state and clientelism" by Alicia Eugenia Silva, published in newspaper El Tiempo on January 30th 2010 during prelectoral period of campaign to Congress in Colombia. This analisis identifies pedagogical components and didactic strategies in the discourse. Besides, it point out manipulation textual elements that induced to reader for take part for writer's interests or informative company. Thus, this ignited a complex process between author and reader based on language, ideology, communication of beliefs, and social interaction.

Key words: Pedagogy, Politics, Manipulation, Opinion Columns. 


\section{Introducción}

En una investigación anterior (Vásquez y Peña, 2013) se realizó un análisis comparativo de la cultura y educación política de los artículos de opinión y páginas de información política en dos diarios: El Colombiano (de tiraje regional y de orientación política conservadora) y El Tiempo (de tiraje nacional y de orientación política liberal), durante las elecciones del Congreso de la República en el 2010, con la finalidad de abordar el problema del análisis del discurso pedagógico de la prensa, mediante la exposición de una matriz categorial híbrida.

De las 22 columnas examinadas ${ }^{1}$ y para este artículo en especial, quisimos seleccionar la de Alicia Eugenia Silva, de El Tiempo, publicada el 30 de enero del 2010, debido a que fue la primera en estudio y pertenecía a un periódico de tiraje nacional como lo es El Tiempo. Además, porque cumplía con las características básicas del género de opinión en cuanto a su dimensión retórica y argumentativa. Por ende, nos servía para señalar todas y cada una de las etapas del proceso de análisis.

La presentación, en este artículo, del método de la investigación se justifica en la medida que ofrece una experiencia de análisis crítico epistémico del discurso que intenta desentramar las posibilidades pedagógicas de los géneros periodísticos, los cuales hacen parte de los dispositivos de educación informal que rodean al ser humano y que potencian los modelos mentales a partir de la producción del conocimiento, puesto que:

"El conocimiento no es un producto natural que 'crece' en las personas, sino que se enseña y se aprende, se genera y se utiliza, se vende y se consume. $\mathrm{Y}$ en todos estos procesos de interacción y transacción están implicados roles sociales, grupos y organizaciones: padres de familia, escuelas, medios de comunicación, políticos, etc.” (Van Dijk, 2010: 176).

En el diseño de la matriz general de la investigación nos basamos en Ciapuscio y Kuguel (2002), investigadores que analizan el componente pedagógico en artículos de divulgación científica; con el fin de analizar la cognición, los procesos mentales sesgados y para una posible manipulación recurrimos a dos modelos de Teun Van Dijk: "Análisis crítico del discurso" (ACD) y el "Análisis crítico epistémico del discurso". Para el presente artículo expondremos los resultados del segundo modelo como paso inicial para identificar las posibilidades pedagógicas de la columna de opinión. De esta manera, se podrá dilucidar si en la columna se hace pedagogía que potencie los conocimientos del lector para la decisión

\footnotetext{
1. El estudio fue desarrollado entre 2010 y 2011 por el grupo Comunicación Pública de la Facultad de Ciencias de la Comunicación de la Universidad Cooperativa de Colombia, sede Medellín, y ha hecho parte de los resultados de la investigación "Análisis comparativo de la cultura y educación política de los artículos de opinión y páginas de información política de los periódicos El Colombiano (Medellín-Antioquia) y El Tiempo (Bogotá-Colombia) para las elecciones de Congreso de la República en el 2010", financiado por el CONADI (Comité Nacional de Investigación), adscrito a la Universidad Cooperativa de Colombia (UCC).
} 
de un voto responsable. Igualmente identificar si en la columna se presentan elementos de manipulación que guíen la votación del elector.

En cuanto a la metodología, hicimos uso del ACD, pero seleccionando la teoría y recursos según el objeto de estudio en concreto; sin embargo, es prudente manifestar que existen muchas formas de abordar el análisis de textos, sobre todo de lo que se pretende buscar en ellos. En primer lugar, se debe tener en cuenta que los discursos que se analizan están en pasado, es decir, se asume que los discursos son históricos y que pueden entenderse y analizarse por referencia a su contexto y a la relación que tienen con otros textos y con otros discursos, pues con seguridad existen conceptos en ellos que fueron tenidos en cuenta en el discurso de análisis. En segundo lugar, el tipo de estudio es hermenéutico, pues luego de hacer un análisis exhaustivo se interpreta bajo los elementos dados por teóricos del análisis crítico del discurso.

Otra característica importante del método en el análisis, según Meyer (2003), es la incorporación de categorías lingüísticas específicas al análisis: estas pueden ser desde categorías discursivas, pragmáticas, como el estudio de la deixis o de las presuposiciones e implicaciones. Sin embargo, puede afirmarse que los autores de trabajos, dentro del análisis crítico del discurso, han tomado los datos de textos de prensa y alocuciones gubernamentales. Específicamente en cuanto a los pasos seguidos para el análisis de los textos, nos limitaremos a presentar lo planteado por Van Dijk, porque consideramos que se adecúa mejor para el modelo de análisis que presentamos. Este autor sugiere que en el análisis deberían tomarse en cuenta aspectos como los siguientes:

- La coherencia local.

- Las supresiones y generalizaciones.

- Las implicaciones y las presuposiciones.

- $\quad$ Actores del discurso.

- La dimensión retórica.

- La ideología y la manipulación.

A partir de lo anterior, el grupo investigador elaboró una serie de fichas bibliográficas sobre citas, conceptos y modelos de análisis propuestos desde los estudios críticos del discurso, las investigaciones sobre el componente pedagógico y la relación conocimiento y discurso; además, tomamos del ACD el modelo de argumentación de Toulmin (1958), que analiza cinco elementos básicos: argumento, conclusión, garantía o ley, soporte o fundamento y modalizador.

Luego de apreciar algunos conceptos en torno a las dimensiones del discurso, centramos la atención en el discurso pedagógico de la prensa. En este sentido, partimos de subrayar que los estudios y reflexiones sobre el discurso pedagógico, como tales, provienen 
tradicionalmente de las esferas de la educación y de las investigaciones del proceso de enseñanza-aprendizaje en el aula de clase. En esta línea, trabajos conceptuales y de aplicación toman relevancia en las últimas décadas a partir de autores como Bernstein (2001) y Lawson (1994). Este último presenta en la década de los noventa el uso de los ciclos de aprendizaje para la enseñanza de destrezas de razonamiento científico y de sistemas conceptuales.

Nuestra propuesta de análisis no pretende asimilar fielmente, y por tanto forzar, la dinámica particular del sistema educativo a las producciones de la prensa, más bien ubica el discurso pedagógico desde quienes "lo usan, recreándolo en la vida con la intención de transformar el conocimiento en una situación común” (Leal Ladrón de Guevara, 2009: 61), enfoque más cercano a los columnistas y géneros de opinión periodísticos.

Sobre el análisis, inferimos que para entender cada argumento o posición, que asume la columnista, es imprescindible tener clara la proximidad de las elecciones parlamentarias y presidenciales, los últimos escándalos de congresistas y su relación del paramilitarismo, la corrupción en la política, así como la actitud y comportamiento político de los votantes.

Pensamos que en la columna de opinión existen orientaciones de índole educativa para los posibles lectores. Sin embargo, puede presentar directrices por parte de la columnista para inducir al lector a votar por candidatos de su preferencia, sobre todo de aquellos que se encuentran indecisos. A todo columnista le resulta difícil mantenerse independiente ante los dueños del medio, en este caso el periódico El Tiempo. Por ende, sus afirmaciones tienden a sesgar información valiosa para el posible votante, lo que conlleva a una manipulación, aprovechando los modelos mentales que se permean en una sociedad de cultura política "parroquial".

\section{Las dimensiones del discurso}

Según Van Dijk (2008: 23), el término discurso es un poco abstracto; no obstante lo caracteriza como un suceso comunicativo de tres dimensiones: $a$ ) el uso del lenguaje; $b$ ) la comunicación de creencias (cognición); y c) la interacción en situaciones de índole social.

Con respecto al uso del lenguaje, es claro que el discurso de las columnas de opinión se dispone a partir de las tipologías textuales preferentemente argumentativas (aunque no se ha descartado el uso de secuencias narrativas o expositivas), como también se circunscribe al estilo periodístico de los géneros de opinión y, por ende, a la naturaleza propia de la columna. Asimismo, el discurso se encuentra cruzado por los preceptos de la retórica, la teoría de la argumentación y por las normas y posibilidades sintácticas, semánticas y pragmáticas.

Consideramos que una mirada a los componentes textuales pedagógicos permitiría identificar la potencia didáctica (del griego didaskein: “enseñar”, “instruir”, “explicar”) que reside en esta clase de artículos de prensa y, de esta manera, integrar el enfoque a las 
estrategias persuasivas (pathos) y lógicas (logos) que despliegan sus autores y que han sido las vertientes tradicionales de creación y análisis de las columnas de opinión.

Dentro de la dimensión cognitiva los estudios del discurso consideran a los lectores como depositarios de algún tipo de conocimiento, así sea superficial, de lo que expone el emisor, que a la luz de Van Dijk (2010: 171) son los "modelos mentales que sirven básicamente como interfaz entre el conocimiento general, abstracto y socialmente compartido, por un lado, y el discurso sobre hechos específicos, por el otro". El mencionado autor explica que un modelo mental es una representación subjetiva (almacenada en la memoria episódica o "autobiográfica", que es parte de la memoria a largo plazo) de un hecho o situación. Dicha representación está presente entre el autor y el lector, con igual o diferente grado de cognición. Por tanto, los lectores necesitan acceder a sus estructuras de conocimiento almacenado en la memoria a largo plazo, activar aspectos relevantes de dicho conocimiento, generar inferencias y utilizar estas para interpretar representaciones textuales con coherencia, o sea, que adquieren nuevos conocimientos que deben ser incorporados e integrados entre los que ya tenían anteriormente. En esta línea Leal Ladrón de Guevara (2009: 52) detalla:

"En general, los seres humanos tenemos que aplicar cierto
'conocimiento del mundo' para establecer una coherencia local
y global, para producir o comprender los tópicos generales o
macroestructuras, para producir inferencias 'de enlace', o para
construir modelos mentales".

Por su lado, Van Dijk (2010) considera las noticias y artículos de opinión como parte de las élites epistémicas que pueden estudiarse desde el "Análisis crítico epistémico del discurso", en tanto las concibe como fuentes primordiales del conocimiento no empírico de los ciudadanos y hasta de los miembros de otras élites.

Con respecto a la tercera dimensión del discurso (situaciones de índole social), cuando se habla de representaciones subjetivas o modelos mentales entre el lector y el autor, se advierte que el conocimiento se presenta en iguales o diferentes grados en cada interlocutor (Ciapuscio y Kuguel, 2002). Por tanto, podemos entender que la relación entre columnista (como especialista o semilego sobre un tema) y lector (como especialista, semilego o lego) puede manifestarse simétrica o asimétricamente.

En este sentido, y aunque en las columnas de opinión la interacción tienda a la simetría cognitiva, el articulista presenta y reactualiza nuevos conocimientos o también ofrece nuevos enfoques argumentativos y retóricos de conocimientos ya compartidos desde su ideología, o desde la disposición discursiva de elementos. Por tanto, se abre la puerta a una relación asimétrica donde el texto es reproductor no solo de conocimiento sino de las relaciones de poder. En consecuencia, es preciso estudiar el discurso de la prensa en consonancia con los procesos cognitivos donde toman parte grupos sociales, ante ello Van Dijk, (2010: 177) afirma:

"Los enfoques habituales pueden ser reemplazados por un análisis mucho más concreto de formas específicas de texto y habla, así 
como por un análisis del modo cómo los miembros de distintos grupos y organizaciones sociales participan a través de distintas situaciones en la expresión (o no) y en la formulación del conocimiento mediante diversas formas de discurso público".

Cabe anotar cómo estas relaciones de poder no solo se dan desde el conocimiento y punto de vista del articulista, como fuente autorizada y legitimada ante los lectores, sino también desde la adhesión e intereses políticos que manifiestan o subyacen en la columna de opinión.

\section{Discurso pedagógico de la prensa}

Cabe anotar que las funciones y estrategias del componente pedagógico se encuentran presentes, por ejemplo, cuando hay descripciones densas de los acontecimientos o se dibuja con palabras el contexto; también cuando se explican esas realidades y se ejemplifican; cuando se dan consejos y se prescriben deberes u obligaciones para los receptores; cuando se hacen paralelos o comparaciones. En sí, el acto pedagógico se encuentra en todas las culturas $y$, al hacer presente todas o algunas de estas funciones, también se hacen visibles el enunciador y el destinatario del conocimiento.

En consecuencia, para configurar una definición del discurso pedagógico (que abarque no sólo la intención del enunciador, al querer transformar el conocimiento del lector, sino también desde los procedimientos retóricos y argumentativos que, carentes de un fin didáctico en sí mismos, puedan analizarse como recursos discursivos de carácter cognitivo y pedagógico) tomaremos ciertas características planteadas por Leal Ladrón de Guevara (2009):

"Una acción social que está inserto en una cultura y un proceso comunicacional intersubjetivo que acude a la ignorancia o cuestionamiento de algo como condición preliminar; además, cuenta con el uso del conocimiento sobre algo. De igual manera parte de un agente-enunciador con conocimiento y creencias, garantizado por criterios de verdad y legitimado por la percepción social; posee un fin didáctico que se hace efectivo mediante destrezas del razonamiento y la expresión de sistemas conceptuales y emplea un método como medio para exteriorizar y representar la realidad".

En esta caracterización dejamos de lado ciertos aspectos que esgrime la autora sobre el discurso pedagógico, tales como: proceso gradual del conocimiento, relación participativa, ambiente formal; puesto que para el caso que nos ocupa aluden más al ámbito del proceso educativo. Claro está que no se desconocen discursos de la prensa que ofrecen conocimiento constante, secuencial y jerárquico más palpable en series pedagógicas y sobre temas concretos (infogramas, separatas, enciclopedias por facsímiles, álbumes temáticos, colecciones, informes especiales...) como también presentan interacción mediada por las nuevas tecnologías (foros, chats, blogs, portales especializados, comentarios...) además 
de ambientes formales en experiencias didácticas, tales como talleres de lectura y de acercamiento a los diarios (prensa escuela) entre otras. De igual forma, para el presente análisis, obviamos de momento secuencias narrativas que configuran series de mensajes que, no obstante la discontinuidad de publicación en los diarios, pueden agruparse de acuerdo con un tema, enfoque y periodo determinados.

\section{Orientación pedagógica de la prensa}

En el proceso del discurso pedagógico el enseñante (agente-enunciador) es quien cumple la función de ofrecer al aprendiente estímulos y orientaciones para lograr el fin didáctico (Leal Ladrón de Guevara, 2009), función que se emite desde una conciencia sobre los procedimientos. En este punto es necesario aclarar que la orientación y los estímulos de los productos discursivos de la prensa no son generalmente contemplados desde objetivos didácticos en sí mismos, como lo anotamos en un apartado anterior, inclusive, géneros periodísticos como el editorial y la columna de opinión se conciben tradicionalmente con el propósito, consciente y declarado (en manuales de estilo y teoría del periodismo) de guiar la opinión de los lectores desde recursos argumentativos, estilísticos y retóricos. Esta aclaración es pertinente en cuanto establece que la orientación pedagógica de un artículo deberá desentramarse desde el análisis discursivo, como sucede con la ideología y la gestión del conocimiento en el ACD y en el análisis crítico epistémico del discurso, respectivamente.

La prensa ha pasado por diversas orientaciones, de acuerdo con una determinada época. Por ejemplo, en el siglo XIX en Colombia los periódicos surgieron, en su mayoría, con una clara y manifiesta orientación ideológica desde la dimensión política, con preferencia por los géneros de opinión y las crónicas, aunque no se desconocen publicaciones o secciones con una marcada tendencia económica, cultural, pedagógica o religiosa. Ya en el siglo XX, con el auge de la noticia, la orientación informativa en los periódicos acaparó la filosofía de los medios como un servicio social para el habitante de la ciudad y desde un enfoque objetivo del mundo. Por tanto, la proporción de los artículos noticiosos redujo la opinión de las empresas periodísticas y de sus colaboradores a páginas determinadas y diferenciadas del cuerpo informativo. No obstante, la objetividad de la prensa fue declarada en contra de críticas epistemológicas, profesionales, ideológicas, entre otras, concretadas desde análisis de contenidos, estudios de producción y recepción de mensajes, análisis críticos del discurso... que pretendían desentramar no sólo el carácter ideológico de los autores que publicaban los géneros de opinión, sino de los reporteros cuando intervenían en textos que gozaban de objetividad como la noticia.

Aunque desde las diversas corrientes investigativas en comunicación (cf. Lozano, 2007), donde la prensa ha sido objeto de estudio, tanto desde de la escuela administrativa estadounidense como de la sociocrítica europea, los enfoques utilitarios, conductistas y críticos han permitido dilucidar orientaciones que trascienden los propósitos básicos de los géneros y plantean procesos de producción y recepción de mensajes desde fines persuasivos, de control, enajenantes, de omisión, de manipulación... 
En cuanto a la manipulación, el ACD traza una línea de estudio que pretende identificar las dinámicas del poder que se concretan en los discursos. Asimismo, tal como sucede en los textos de la prensa, en el discurso pedagógico se presenta un juego de poder. Bernstein describe el discurso pedagógico como:

"La regla que inserta un discurso de competencia en un discurso de orden social, en donde el segundo, ejerce dominancia sobre el primero. La comunicación especializada, mediante la cual se realiza la transmisión-adquisición entre los sujetos pedagógicos, se puede constatar a partir de la dominancia del discurso regulador, a los cuales llama agentes discursivos dominantes (médicos, arquitectos, profesores, periodistas, etc.), revelándonos una postura que está fuertemente sesgada por la fuente de poder de las ideologías del discurso" (ápud Ladrón de Guevara, 2009: 56).

\section{Resultados}

\subsection{Un ejemplo en el análisis crítico del discurso pedagógico}

El texto que elegimos para presentar el análisis fue la columna titulada "Estado de opinión y clientelismo" (30/I/2010), por Alicia Eugenia Silva, articulista del diario El Tiempo de Bogotá. Nos llamó la atención porque hemos venido trabajando con un corpus mucho más amplio que está constituido por diferentes columnas y noticias; incluso de dos periódicos, pero esta columna fue la primera que cayó en nuestras manos para la época preelectoral de elecciones del Congreso colombiano. A continuación transcribimos la columna:

\section{"Estado de opinión y clientelismo}

El 14 de marzo los colombianos irán a las urnas para elegir el próximo Congreso. Las elecciones a corporaciones públicas en Colombia son las que menos sorpresas dan y aunque siempre llegan caras nuevas, la mayoría de los congresistas primíparos heredan sus curules de caciques regionales, de padres inmolados por la violencia o de abuelos recordados por la ciudadanía.

Los votos de opinión son muy pocos. En el 2006, menos del 5 por ciento de los electores votaron por senadores sin mayores ataduras con las maquinarias de la política tradicional. Quienes alcanzaron curules en el senado fueron Gina Parody (87.297 votos), Marta Lucía Ramírez (68.405), Cecilia López Montaño (32.558) y Alfonso Valdivieso Sarmiento (13.970), entre otros. Las senadoras de 'la U' y el senador de Cambio Radical recogieron votos de opinión con las banderas del uribismo, mientras que la senadora liberal logró apenas llegar, gracias a haber sido la cabeza de lista 
de su partido. Los votos de los Visionarios con Antanas (71.843) se perdieron, al igual que los del País que Soñamos, de Peñalosa (165.981), por cuanto ninguno alcanzó el umbral necesario. Los peñalosistas que llegaron a la Cámara por Bogotá, con un poco más de 100.000 votos, hoy militan en el antiguo partido de su jefe, es decir, en el Partido Liberal.

Los votos atados al clientelismo tradicional son muchísimos. La mayoría de los senadores del partido de 'la U' son antiguos liberales, el diezmado Cambio Radical recoge con su jefe, Germán Vargas, herencias del llerismo, mientras que el Partido Conservador mantiene sus seguidores y se precia de ser el partido más antiguo del país. Las minorías liberales se agrupan en el Partido Liberal y el Polo recoge la izquierda tradicional y uno que otro liberal de antaño. Los nuevos partidos como el PIN y ADN, vinculados a la 'parapolítica', parecen haberse reorganizado desde las cárceles colombianas y algunos entes territoriales que todavía controlan.

Las listas de opinión del 2010 se limitan a las de los ex alcaldes de Bogotá y Medellín. En el caso de los verdes, juntaron al político más anti clientelista que ha pasado por Bogotá con un clientelista rosa y un descarado clientelista rojiamarillo. Esta unión está pegada con alas de cucaracha. A última hora, los ex alcaldes bogotanos decidieron, como Warren Buffett, adquirir una empresa electoral quebrada con miras a sacar utilidades políticas para ellos. A lo mejor les funciona, aunque la política no siempre se comporta como los negocios. El primer alcalde del Polo en Bogotá hizo clientelismo ostensible con los rojos samperistas y los amarillos polistas, a quienes les heredó el manejo del presupuesto de la ciudad. Hoy, estos altos funcionarios del Distrito sienten que no existe ningún tipo de impedimento para llevar en la lista de senado al hermano del Alcalde y al esposo de la Secretaria de gobierno.

El ex alcalde de Medellín decidió recorrer una ruta distinta. Hace dos años camina por Colombia recogiendo firmas para su inscripción y la de su Selección Colombia. Comenzó sentando las bases para un movimiento político con presencia regional. En los últimos meses su Movimiento, Compromiso Ciudadano por Colombia, se dio a la tarea de conformar una lista con candidatos mayoritariamente independientes, como Juan Carlos Flórez (Bogotá), Beatriz White (Medellín), Fernando Giraldo (Cartago), María Piedad Velasco (Cali), Christian Argüello (Bucaramanga), Rodrigo Lara Sánchez (Neiva), Virginia Gómez (Barranquilla) o Claudia Fadul (Cartagena). 
Los pocos colombianos que constituyen el voto de opinión deben escoger entre la Selección Colombia de Fajardo y la Unión Temporal de los Verdes. El Estado de Opinión parece abrirse camino en Colombia sin muchos votos de opinión que lo respalden. El 95 por ciento del Congreso estará constituido por el más puro clientelismo y los llamados independientes se deberán conformar con disputarse cinco curules.

Por consiguiente, la lista que logre tres o más curules por fuera del clientelismo tradicional deberá considerarse ganadora del voto de opinión, así el clientelismo barra con todo lo demás".

\subsection{Tema}

Los temas de un discurso comprenden la información más relevante del texto, o en palabras de Van Dijk (2004: 22):

"Representan el significado global y son técnicamente descritos como 'macro estructuras semánticas', son quizás las estructuras 'más importantes del discurso' ya que controlan la coherencia total, los significados locales, la comprensión total y nuestra memoria del discurso; son generalmente lo que mejor recordamos del discurso $\mathrm{y}$, lo que por tanto, también tiene más impacto en nuestra mente, tal como los modelos mentales y las representaciones sociales que se forman o cambian gracias a la comprensión del discurso".

Una vez dividido el discurso en proposiciones, se aplicaron las macro reglas de supresión, generalización y construcción. Según Van Dijk (1996: 48), "la supresión consiste en dejar solo las proposiciones pertinentes y que desempeñaban un papel básico en el discurso, mientras que la generalización implica que de una secuencia de proposiciones, se hace una proposición que contenga un concepto derivado de toda la secuencia y la proposición así construida sustituye a la secuencia original". Por tanto, al dejar las proposiciones pertinentes y suprimir las restantes, se arma una proposición de toda la secuencia original, dando como resultado la generalización de la columna:

"Los votos de opinión son pocos. Los votos atados al clientelismo tradicional son muchísimos. Las listas de opinión del 2010 se limitan a las de los ex alcaldes de Bogotá, quienes adquirieron una empresa electoral quebrada para sacar utilidades políticas, y al ex alcalde de Medellín. Los pocos colombianos que constituyen el voto de opinión deben escoger entre la Selección Colombia de Fajardo y la Unión Temporal de los Verdes".

Para la macro regla denominada construcción, se parte de la nueva secuencia de proposiciones y se elabora una proposición que sintetice el mismo hecho denotado por la 
totalidad de la secuencia de proposiciones, y se sustituye la secuencia original por la nueva proposición, de tal forma que en el artículo en estudio el tema es el estado de opinión frente al clientelismo en Colombia, donde Alicia Eugenia Silva contrasta el gran número de votos atados al clientelismo tradicional con las pocas opciones del voto de opinión, entre ellas la unión temporal de los exalcaldes de Bogotá y la ruta anticlientelista de Sergio Fajardo.

El tema o tematización de la columna de opinión se sintetiza en el estado de opinión frente al clientelismo en Colombia. Por ende, esta idea tutelar concentra la coherencia global del texto y posee mayores probabilidades de fijarse en la memoria del lector, proponiendo que no hay esperanza de una cambio profundo en los resultados de las elecciones al Congreso de la república, puesto que predomina el voto clientelista al sufragio de opinión. Ergo, existe un incipiente Estado de Opinión.

\subsection{Coherencia local}

A la luz de Van Dijk (2010: 181):

"El análisis de la coherencia en la secuencia de proposiciones, tanto en su faceta referencial (basado en modelos) como en su faceta intensional ${ }^{2}$ (basado en significados), revela cómo el conocimiento se organiza, por ejemplo, en estructuras causales, y de este modo nos permite conocer de qué manera los autores gestionan la explicación de hechos sociales y políticos”.

Veamos la estructura en la columna que tomamos de ejemplo:

I. Las elecciones a corporaciones públicas en Colombia son las que menos sorpresas dan.

II. y aunque siempre llegan caras nuevas, la mayoría de los congresistas primíparos.

III. heredan sus curules de caciques regionales, de padres inmolados por la violencia o de abuelos recordados por la ciudadanía.

IV. Los votos de opinión son muy pocos.

V. Los votos atados al clientelismo tradicional son muchísimos.

2. Para Van Dijk lo "intencional" (con S) se refiere al significado, mientras lo "extensional" consiste en las entidades a las cuales una expresión se aplica. Un ejemplo de esta situación se presenta cuando la columnista Silva denomina una misma entidad del estado (extensional) como Congreso y Corporación pública, pero es claro que ambos lexicalizadores, aunque sinónimos difieren en su connotación. 
La secuencia de las tres primeras proposiciones denota eventos relacionados entre sí en un modelo mental del emisor y también del destinatario, pues para nadie es un secreto que en Colombia se presenta esta situación. Además de esta coherencia de índole referencial, el texto puede ser localmente coherente si sus proposiciones están relacionadas unas con otras, como cuando una proposición aporta una generalización, especificación, ejemplificación, contraste, etc., con respecto a una proposición anterior o posterior. Véase, por ejemplo, la secuencia de las proposiciones cuarta y quinta: allí existe un contraste que el emisor lo explica en el artículo con estadísticas y que varios lectores o destinatarios ignoran esos datos que se encuentran en las proposiciones menos relevantes; en otras palabras, puede interpretarse como una opinión, debido a que contiene una expresión calificativa y cuyo modelo mental no tiene por qué estar necesariamente basado en un conocimiento comúnmente aceptado por la totalidad de los destinatarios o lectores.

Ciapuscio y Kuguel (2002) dicen que un texto es divulgativo cuando el contenido especializado se retoma para ser transmitido a un destinatario lego, con el fin de que conozca esa información y además que la tenga en cuenta en su vida cotidiana. En la columna, objeto de estudio, la articulista es la especialista, la conocedora de la situación que vive el país políticamente; es la enunciadora pedagoga que cuantifica y que aconseja.

Asimismo, Bosio (2011) plantea que el procedimiento de comparación/contraste es un recurso de gran impacto didáctico, impacto que en el discurso se hace visible cuando busca favorecer a los partidos de oposición frente a los partidos de coalición y todo lo hace a través de la descripción y la ilustración de hechos que, como ya se dijo, le sirven al destinatario no experto para que pueda completar la representación semántica del discurso.

\subsection{Los actores en el discurso}

Van Leeuwen determina que "el discurso trata sobre la gente, y por tanto, es determinante dilucidar la cuestión de cómo se retrata a las personas, qué identidades y roles se les atribuyen, qué relaciones se trazan entre ellas, qué afiliaciones se describen, etc." (ápud Van Dijk, 2010: 181). Estas descripciones hacen parte del espacio para conocer la posición entre el "nosotros" y el "ellos", entre los miembros de un mismo grupo y el de los demás grupos; de tal forma que se pueda descubrir el carácter ideológico del enunciador.

En ese mismo sentido, Capellino (2009) vislumbra que las operaciones más comunes del enunciador pedagógico, además de dar consejos y cuantificaciones, es hacer un contrato entre un "nosotros" y un "ustedes" (explícita o implícitamente) donde el nexo establecido entre esas partes es desigual, una informa, sabe, guía, y la otra no sabe, es más o menos pasiva.

En el caso que nos ocupa, el enunciador tiene el conocimiento y genera su propia opinión con respecto a los actores que hacen parte del discurso. La descripción de los actores devela los hechos y acciones de ellos, combinando el conocimiento general y el sentido común compartido por el enunciador y los destinatarios, obviamente con elementos de valoración ideológica. Por eso la descripción de los actores que se detalla en la columna en estudio muestra cuál es la postura ideológica de la articulista, pues ella pinta con palabras cuáles de 
esos actores son los contrarios y cuáles los que apoya. De hecho, hay una postura didáctica al hacer comparaciones y contrastes; pero también está presente el elemento manipulador o que busca cierta complicidad con el lector. En este aspecto, el enunciador (en busca de complicidad) establece un lugar de común acuerdo, como si los destinatarios o muchos de ellos, tuvieran la misma visión del mundo y, por ende, estuvieran de acuerdo con lo dicho en el discurso (ibídem).

En este caso específico quien escribe es Alicia Eugenia Silva ${ }^{3}$. Los demás actores que están presentes en el discurso son precisamente a los que ella alude en la columna, tales como los colombianos, los partidos, los candidatos, los mandatarios, entre otros.

\subsection{Implicaciones y presuposiciones}

El uso de expresiones modalizadoras o cromatizadoras, que en términos de Van Dijk (2010) son aquellas que califican lo nombrado, tales como: caras (nuevas), congresistas (primíparos), caciques (regionales), padres (inmolados), abuelos (recordados), entre otras, aportan un juicio valorativo; luego estas expresiones son descripciones generalmente reconocidas por muchos destinatarios y, por tanto, constituyen conocimiento compartido, pues son valoraciones que, según gocen de un mayor o menor grado de aceptación, podrán considerarse como opiniones o como actitudes políticas ampliamente compartidas aunque estas palabras pueden ser interpretadas de manera diferente según los modelos mentales del columnista y de los destinatarios del mensaje.

Los cromatizadores deben ser, además de conocidos, argumentados por el columnista; pero aun así se deja traslapada cierta manipulación, como lo veremos más adelante, independientemente que esté utilizando estrategias didácticas al explicar, ejemplificar, aconsejar, contraponer, etc. Es el caso de las expresiones "descarado clientelista rojiamarillo" y "empresa electoral quebrada", que no están muy claras, por ejemplo el término "descarado", da a entender que es uno de los actores políticos sin escrúpulos, pero no lo argumenta, no lo explica y no dice de quién se trata. De igual forma, el modalizador "clientelista rojiamarillo", actor que hace parte de lo que ella llama "empresa electoral quebrada" y cuyo único concepto es que "está pegada con alas de cucaracha", juicio negativo que resalta lo malo del otro grupo.

Van Dijk (2010) sostiene que uno de los elementos más importantes del discurso es lo que no se dice y queda implícito. Estos pueden ser modelos semánticos de los hechos sobre los que se habla. Analicemos algunas de estas implicaciones:

\footnotetext{
3. Ex secretaria de Gobierno en la Alcaldía de Bogotá, bajo la administración de Antanas Mockus, llegó a ser considerada como "la mujer detrás del trono". Después de la renuncia de Mockus a la alcaldía, integró la terna para sucederlo. Más tarde hizo parte del equipo asesor en la campaña de Sergio Fajardo. Se la voceó como candidata para el Congreso, pero se encontraba inhabilitada.
} 
"Los votos de opinión son muy pocos. En el 2006, menos del 5 por ciento de los electores votaron por senadores sin mayores ataduras con las maquinarias de la política tradicional. Quienes alcanzaron curules en el senado fueron Gina Parody (87.297 votos), Marta Lucía Ramírez (68.405), Cecilia López Montaño (32.558) y Alfonso Valdivieso Sarmiento (13.970), entre otros".

Afirma Van Dijk (1996: 21-22): "las opiniones no siempre necesitan ser expresadas explícitamente en una proposición, sino que pueden estar implicadas". De igual forma, plantea que "las proposiciones pueden estar implicadas, ya que se exponen para ser sabidas (ciertas), o presupuestas, según un modelo previo de un hecho. Estas pueden utilizarse estratégicamente, para introducir de manera indirecta en un texto proposiciones que pueden no ser ciertas en absoluto." Este también es el caso de las presuposiciones que incorporan opiniones. Así pues, en el ejemplo se presuponía que en realidad los actores mencionados en el artículo son votos de opinión lejanos a las maquinarias, cuando de hecho se tiene conocimiento por parte de los destinatarios que todos pertenecen a los partidos y movimientos que están dentro de las maquinarias políticas tradicionales. Además, para dar más veracidad a lo dicho, adjunta los datos reales del número de votos que obtuvieron en las elecciones del 2006.

Es evidente que este discurso contiene variedad de implicaciones y presuposiciones que, para el tema de nuestra investigación, están basadas en conocimientos personales, sociales y con fuentes gubernamentales, tales como los datos numéricos de la cantidad de votos en elecciones anteriores. Luego es un conocimiento social y político compartido con muchos de los destinatarios y que puede ganar en credibilidad cuando los hablantes consiguen atribuir a fuentes fiables el conocimiento o las opiniones que expresan. Este recurso se activa especialmente en casos en los que el destinatario podría dudar de los conocimientos u opiniones del enunciador.

Al profundizar el contenido del artículo, la columnista cuenta con presupuestos que comparte con muchos de los lectores. A manera de ejemplo: historia del clientelismo, transfuguismo entre partidos, herencias políticas, sistema democrático por sufragio, parapolítica, etc. De igual forma, su papel consiste en advertir y denunciar la falta de un Estado de opinión en Colombia ante las elecciones al Congreso. Asimismo, critica la unión de los exalcaldes de Bogotá y exime de clientelismo a Sergio Fajardo.

\subsection{Análisis argumentativo}

En la columna en estudio se hacen visibles las explicaciones a través de varios argumentos (figura 1). Obviamente de cada argumento sale a flote una conclusión basada en el conocimiento sociocultural compartido entre el enunciador y los destinatarios. Igualmente, hay que tener en cuenta la garantía, pues viene a ser el conocimiento compartido entre el emisor y el lector y con un soporte que apoya ese garante. Asimismo, aparece el elemento modalizador que es el que expone el grado de certeza y lo que más se acerca a lo manifestado en el argumento. Veamos algunos argumentos que están presentes en la columna: 
Figura 1: Cuatro argumentos que aparecen en la columna de Alicia Eugenia Silva.

\begin{tabular}{|c|c|}
\hline Argumento 1 & $\begin{array}{l}\text { El } 14 \text { de marzo los colombianos irán a las urnas para elegir el próximo Congreso y } \\
\text { aunque siempre llegan caras nuevas, la mayoría de los congresistas primíparos heredan } \\
\text { sus curules de caciques regionales, de padres inmolados por la violencia o de abuelos } \\
\text { recordados por la ciudadanía. Los votos atados al clientelismo son muchísimos. Los } \\
\text { votos de opinión son pocos. }\end{array}$ \\
\hline Conclusión & Las elecciones a corporaciones públicas en Colombia son las que menos sorpresas dan. \\
\hline Garantía-Ley & $\begin{array}{l}\text { Implícita: si no cambia la naturaleza ética y la cultura política de los candidatos } \\
\text { y partidos con respecto al clientelismo, no deben esperarse resultados electorales } \\
\text { enfocados en votos libres o de opinión. }\end{array}$ \\
\hline $\begin{array}{l}\text { Soporte - } \\
\text { fundamento }\end{array}$ & Sistema electoral, cultura política, alianzas, hechos históricos. \\
\hline Modalizador & Menos, mayoría. \\
\hline Argumento 2 & $\begin{array}{l}\text { La mayoría de los senadores del partido de "la U" son antiguos liberales, el diezmado } \\
\text { Cambio Radical recoge con su jefe, Germán Vargas, herencias del llerismo, mientras que } \\
\text { el Partido Conservador mantiene sus seguidores y se precia de ser el partido más antiguo } \\
\text { del país. Las minorías liberales se agrupan en el Partido Liberal y el Polo recoge la } \\
\text { izquierda tradicional y uno que otro liberal de antaño. Los nuevos partidos como el PIN } \\
\text { y ADN, vinculados a la "parapolítica", parecen haberse reorganizado desde las cárceles } \\
\text { colombianas y algunos entes territoriales que todavía controlan. }\end{array}$ \\
\hline Conclusión & Los votos atados al clientelismo tradicional son muchísimos. \\
\hline Garantía-Ley & $\begin{array}{l}\text { Implícita: cuando en una democracia la mayoría de candidatos políticos pertenecen a } \\
\text { los partidos, antiguos y nuevos, que tienen comprobados antecedentes clientelistas, se } \\
\text { espera que los votos estén sujetos a ese sistema de política parroquial. }\end{array}$ \\
\hline $\begin{array}{l}\text { Soporte - } \\
\text { fundamento }\end{array}$ & Historia de los partidos, trayectoria de jefes y candidatos, procesos judiciales. \\
\hline Modalizador & La mayoría, se precia, uno que otro, parecen haberse, algunos. \\
\hline Argumento 3 & $\begin{array}{l}\text { A última hora, los ex alcaldes bogotanos decidieron, como Warren Buffett, adquirir una } \\
\text { empresa electoral quebrada con miras a sacar utilidades políticas para ellos. A lo mejor les } \\
\text { funciona, aunque la política no siempre se comporta como los negocios. El primer alcalde } \\
\text { del Polo en Bogotá hizo clientelismo ostensible con los rojos samperistas y los amarillos } \\
\text { polistas, a quienes les heredó el manejo del presupuesto de la ciudad. Hoy, estos altos } \\
\text { funcionarios del Distrito sienten que no existe ningún tipo de impedimento para llevar en } \\
\text { la lista de senado al hermano del Alcalde y al esposo de la Secretaria de gobierno. }\end{array}$ \\
\hline Conclusión & $\begin{array}{l}\text { En el caso de los verdes, juntaron al político más anticlientelista que ha pasado por } \\
\text { Bogotá con un clientelista rosa y un descarado clientelista rojiamarillo. }\end{array}$ \\
\hline Garantía-Ley & $\begin{array}{l}\text { Implícita: cuando existe nepotismo y alianzas para lograr votos entre los miembros de } \\
\text { partidos, así sean de partidos no tradicionales, se advierte el carácter clientelista. }\end{array}$ \\
\hline
\end{tabular}




\begin{tabular}{|l|l|}
\hline $\begin{array}{l}\text { Soporte - } \\
\text { fundamento }\end{array}$ & $\begin{array}{l}\text { Normatividad electoral, normas éticas, legislación sobre contratación pública, normas } \\
\text { internas de partidos. }\end{array}$ \\
\hline Modalizador & $\begin{array}{l}\text { A última hora, como Warren Buffet, A lo mejor les funciona, aunque, no siempre, } \\
\text { sienten. }\end{array}$ \\
\hline Argumento 4 & $\begin{array}{l}\text { Los pocos colombianos que constituyen el voto de opinión deben escoger entre la } \\
\text { Selección Colombia de Fajardo y la Unión Temporal de los Verdes. El 95 por ciento del } \\
\text { Congreso estará constituido por el más puro clientelismo y los llamados independientes } \\
\text { tres o más confules por fuera del clientelismo tradicional deberá considerarse ganadora } \\
\text { del voto de opinión, así el clientelismo barra con todo lo demás. }\end{array}$ \\
\hline Conclusión & $\begin{array}{l}\text { El Estado de Opinión parece abrirse camino en Colombia sin muchos votos de opinión } \\
\text { que lo respalden. }\end{array}$ \\
\hline Garantía-Ley & $\begin{array}{l}\text { Implícita: cuando existe una mayoría de candidatos clientelistas como opción en una } \\
\text { contienda electoral, se considera que existe un incipiente Estado de opinión. }\end{array}$ \\
\hline $\begin{array}{l}\text { Soporte } \\
\text {-fundamento }\end{array}$ & Constitución política, estadísticas, resultados electorales históricos, conceptos de Estado. \\
\hline Modalizador & Parece (abrirse), sin muchos (votos), los pocos, más puro. \\
\hline
\end{tabular}

Fuente: Elaboración propia, basada en Silva (2010).

Las anteriores estructuras discursivas de tipo argumentativo son una de las principales estrategias que utiliza la columnista para demostrar que sus creencias y opiniones son un conocimiento compartido con los lectores. Para ello acude a premisas implícitas y explícitas sobre hechos de la cultura política en Colombia, sostenidas con evidencias y fuentes institucionales, estadísticas e históricas.

Ahora bien, se dejan entrever en la columna algunos deónticos o elementos que valoran y prescriben algo como correcto o incorrecto; son expresiones de "deber ser". Se han gramaticalizado en modo imperativo o verbos modales: deber, poder, tener que, haber que, haber de: implican tareas que complementen el entorno pedagógico. Se han universalizado y significan un "compromiso" entre enunciador y destinatario. En la columna de estudio encontramos tres: a) "Deben escoger entre la Selección Colombia de Fajardo y la Unión Temporal de los Verdes"; b) "Se deberán conformar"; y c) "Deberá considerarse ganadora del voto de opinión".

\subsection{Dimensión retórica}

Van Dijk (2002b: 21) manifiesta que en el discurso la mayor parte de su significado está escondido (implícito) y no es explícitamente dicho por el texto. Si se sabe sobre qué trata el discurso, se pueden deducir muchos otros significados. Muchas de las estructuras específicas, en varios niveles de descripción del discurso, al que algunas veces llamamos de 
"retórica"" tales como metáforas, símiles, hipérboles, ironías, etc., requieren conocimiento del mundo, no solo como conocimiento personal o creencia, sino como conocimiento grupal o social.

Según Van Dijk (2010: 182), las metáforas "representan nuestra conceptualización corporeizada, experiencial del conocimiento abstracto y complejo del mundo, y la elección de metáforas es, por tanto, crucial para nuestra comprensión de los hechos sociales y políticos". El autor agrega que las metáforas son recursos semánticos que sirven para comprender, representar y experimentar el mundo y, con él, nuestros conocimientos y opiniones.

Cuando la columnista dice en su escrito: "Sin mayores ataduras con las maquinarias de la política tradicional", es una forma clásica de conceptualizar los nexos entre aquellos que han gobernado sin permitir un cambio, con los gobernados que se dejan comprar los votos. "Las metáforas se pueden emplear como medio para explicar hechos complejos o defender opiniones y actitudes igualmente complejas; pues todo discurso presupone que los hablantes tienen conocimiento aproximado (buenas deducciones) sobre lo que los receptores saben, y utilizan varias estrategias para equiparar así sus discursos a las condiciones del contexto" (Van Dijk: 2002b: 16). De ahí que las figuras retóricas sean parte esencial en el análisis pedagógico, pues no solo explican temáticas, sino que amplían información a través de los ejemplos, paralelos, descripciones, etc.

Ahora bien, ¿qué incidencias tienen las metáforas y cuál es su valor? Lakoff y Johnson (1980: 147) sostienen que todo proceso del pensamiento humano es en gran medida metafórico. En otras palabras, la metáfora más allá de ser un elemento lingüístico, permite estructurar conceptos a partir de otros y la forma en que nos relacionamos con otras personas. Los mismos autores sostienen que muchas de las semejanzas que percibimos son el resultado de metáforas convencionales que forman parte de nuestro sistema conceptual y de nuestras creencias.

En la columna en estudio encontramos varias metáforas: "recogieron votos de opinión", "con las banderas del uribismo", "los votos atados", "herencias del llerismo", "esta unión está pegada con alas de cucaracha", "empresa electoral quebrada". Las metáforas marcan hitos ya conocidos por los lectores, pero la repetición y acentuación sobre algunos temas refuerzan el conocimiento particular y generan un conocimiento más social, compartido por muchos lectores y generando expectativas para los mismos. Por lo tanto, cabría preguntarnos: ¿Qué expectativas genera el contexto en la columna?

Se habla del proceso electoral del 14 de marzo del 2010; pero también de cómo han sido los debates electorales en el pasado, en el cual se manifiesta que ha sido de mucho clientelismo y poco voto de opinión. La columnista dirige sus argumentos a los electores colombianos, en especial a los que no han definido su intención de voto. De igual forma, la columnista es conocida en el medio de comunicaciones, sabe de política y ha trabajado en ella con algunos de los candidatos mencionados en su columna. Por último, su rasgo es el de retórica de la promulgación, pues su discurso es argumentado y expone en él verdades que son conocidas 
por muchos electores. Sin embargo, genera dudas sobre comentarios de algunos políticos donde no es clara la afirmación acerca de ellos.

Otra pregunta sería: ¿Qué es lo que el texto presenta al público? La columnista maneja un tono impersonal, con ausencia de referencias personales. Existe un auditorio real que es el elector colombiano de a pie, así como los dirigentes de partidos y movimientos políticos. Sin embargo, hay uno implícito que es aquel colombiano que aún no ha definido su voto, pero que gracias a la lectura de la columna lo puede hacer. Sin embargo, la percepción del contexto es desesperanzadora, apocalíptica, pues dice que todo seguirá igual, o sea que predominará de nuevo el voto clientelista frente al de opinión.

\subsection{Ideología}

En este apartado queremos destacar aquellas ideologías definidas como identidad personal y de grupo, actividades que realizan, objetivos y los componentes axiológicos como valores éticos y morales que permean el discurso en estudio. Empecemos entonces con las descripciones que identifican al grupo:

- ¿Quién es Alicia Eugenia Silva? Además de columnista de la casa El Tiempo, es participante en política, exfuncionaria de la administración distrital de Bogotá y miembro activo de las campañas de Antanas Mockus y Sergio Fajardo.

- ¿De dónde viene? Ella y sus grupos políticos vienen de movimientos alternativos, en cuanto a sus formas proselitistas, independientes de los partidos tradicionales, aunque ella estuvo en contacto con el Liberalismo de César Gaviria.

Descripciones de actividad:

- ¿Cuál es su tarea como integrante del grupo? Aconsejar a los lectores sobre el incipiente estado de opinión en el país, el gran clientelismo que atenta contra ese estado, promover criterio frente a la votación, advertir sobre la cultura política clientelista y destacar a Sergio Fajardo.

- ¿QQué es lo que hace? Opinar sobre la cultura política, rechazando el clientelismo y apoyando el proselitismo alternativo de los independientes.

- ¿Qué se espera del grupo? Argumentación, idoneidad, conocimiento personal, grupal y cultural.

\subsection{Descripciones de posición y de relación}

Muchas ideologías de grupos incluyen la representación de sí mismos y de los otros, 
de "nosotros" y "ellos". Sin embargo, algunas ideologías se contraponen cuando nos presentamos como buenos, pero ellos son malos, sobre todo de acuerdo a los intereses que se quieran manejar.

La presentación positiva nuestra y la presentación negativa de los otros pueden influir en las opiniones de los lectores, ya que pueden están caracterizadas por proposiciones de juicios de valor, pueden presentar actitudes colectivas de prejuicio social hacia grupos minoritarios. Por ejemplo, en la presentación favorable de candidatos pertenecientes a la política tradicional como si fueran candidatos de opinión; pero desfavorables cuando se presenta la unión de candidatos que han sido de izquierda con los llamados "cívicos anticlientelistas" o cuando no se menciona el nombre de la dirigente liberal que ha salido electa por ser cabeza de lista. Según Van Dijk (2010), las ideologías pueden representarse como autoesquemas de grupos, caracterizados por categorías tales como "pertenencia" (¿quién pertenece al grupo?, ¿quién puede ser admitido?), actividades (¿qué hacemos?), objetivos (¿por qué hacemos esto?), valores (¿cómo deberíamos hacer esto?), posición (¿adónde estamos situados?, ¿cuáles son nuestras relaciones con otros grupos?) y recursos (¿qué tenemos? y ¿qué no tenemos?).

La forma en que los grupos y sus miembros se representan a sí mismos y representan a los demás puede estar "sesgada", considerada desde el punto de vista de otros (incluido también el nuestro, como analistas). Aplicadas a los periodistas como grupo, estas categorías ideológicas incluirán la información básica acerca de quién es reconocido como periodista: ¿Cuál es el trabajo típico de los periodistas? (por ejemplo, redactar noticias y editoriales), sus objetivos (informar al público), sus valores y normas (verdad, credibilidad, imparcialidad), su posición con respecto a los lectores o autoridades y su recurso típico: como grupo (información).

\subsection{La manipulación}

La estrategia de polarización que está basada entonces en la descripción positiva del propio grupo y descripción negativa del grupo ajeno, presenta lo que Van Dijk (1996: 21) llama "cuadrado ideológico", que consiste en: " $a$ ) resaltar nuestras buenas propiedades/acciones; b) resaltar sus malas propiedades/acciones; $c$ ) mitigar nuestras malas propiedades/acciones; d) mitigar sus buenas propiedades/acciones".

La dimensión social de la manipulación se ha examinado en términos de abuso de poder por las élites y dirigentes que tienen acceso al discurso público y manipulan grupos de personas a favor de sus propios intereses. Este tipo de discurso se presenta más escrito y en grupos como políticos, docentes y periodistas o columnistas que utilizan el conocimiento de los hechos políticos y lo transforman en modelos mentales reconocidos por unos lectores, pero desconocidos por otros, controlando así la presentación positiva de uno mismo y la negativa de los otros.

Van Dijk (2006: 53) arguye que para estar en condiciones de manipular a muchos otros a través del texto oral o escrito, se necesita tener acceso a alguna forma de discurso 
público, como los debates parlamentarios, las noticias, artículos de opinión, textos de estudio, artículos científicos, novelas, programas de televisión, propaganda, Internet, etc. Agrega que si los medios entregan información incompleta o prejuiciada de alguna manera acerca de un político específico durante una campaña electoral para influir en los votos de los electores, estaríamos frente a un caso de manipulación si suponemos que los lectores tienen el derecho a estar "debidamente" informados acerca de los candidatos en una elección.

En la columna se hace visible la manipulación en dos casos específicos que a continuación mostraremos:

- "Los votos de opinión son muy pocos. En el 2006, menos del 5 por ciento de los electores votaron por senadores sin mayores ataduras con las maquinarias de la política tradicional. Quienes alcanzaron curules en el senado fueron Gina Parody (87.297 votos), Marta Lucía Ramírez (68.405), Cecilia López Montaño (32.558) y Alfonso Valdivieso Sarmiento (13.970), entre otros".

- "En el caso de los verdes, juntaron al político más anticlientelista que ha pasado por Bogotá con un clientelista rosa y un descarado clientelista rojiamarillo. Esta unión está pegada con alas de cucaracha”.

En el primer caso, se sostiene que los políticos mencionados tienen voto de opinión, así pertenezcan a las maquinarias, cuando es precisamente el no estar en maquinarias y componendas políticas el aliciente para tener voto de opinión, entendiéndose este $\mathrm{y}$, como se dijo más arriba, que no se compra ni se vende al mejor postor, sino que se hace con una cultura política verdaderamente participativa y democrática.

En el segundo punto, no hay información alguna con respecto a quién es el descarado "rojiamarillo". Está prejuiciada y malintencionada. Por supuesto que esto influye en los enunciatarios y más en época electoral, pues se utiliza la columna como mecanismo de interacción y puesta en escena de significados, produciendo un sentido manipulador. Lo anterior no significa que un periódico no pueda apoyar o favorecer a su propio candidato, pero debiera hacerlo mediante una información adecuada y persuasiva, no mediante manipulación omitiendo información importante, mintiendo o distorsionando los hechos de los políticos mencionados.

La descripción de los actores en la columna muestra cuál es la postura ideológica de la articulista, ya que pinta con palabras cuáles de esos actores son los contrarios y cuáles los que apoya. De hecho, hay una postura didáctica, al hacer comparaciones y contrastes, pero también está presente el elemento manipulador o que busca cierta complicidad con el lector. La columnista emplea una entonación fuerte para enfatizar ideas y marcar las valoraciones negativas en unos candidatos. Empero, destaca a Sergio Fajardo y la "Selección Colombia". 


\section{Conclusiones}

- Las dimensiones del discurso en la columna en estudio del periódico El Tiempo fueron elaboradas con un conocimiento amplio sobre procesos electorales y la situación política que se vive en el país. La articulista presenta y reactualiza nuevos conocimientos. Además, ofrece nuevos enfoques argumentativos y retóricos ya compartidos desde su ideología y desde la disposición discursiva de elementos trabajados en la columna. La acción general del artículo consiste en describir, argumentar, ejemplificar, explicar y comparar el estado de clientelismo en Colombia para augurar un resultado incipiente con respecto de los votos de opinión en las elecciones para congreso del 2010. Estas estrategias configuran un discurso pedagógico, en cuanto son secuencias de gestión del conocimiento. No obstante, la posición asumida por la columnista y la presencia de algunos elementos manipuladores en el artículo. La columna de opinión analizada desde el componente pedagógico y de los elementos manipuladores, ratifica que no solo se despliegan recursos de la retórica, la teoría de la argumentación o la preceptiva periodística, sino que alberga un control del saber y una comunión de modelos mentales con una potencia didáctica que se concreta en el texto mediante recursos, tales como: tratamiento del tema y de los actores, prejuicios, metáforas, comparaciones, ejemplos, casos y secuencias narrativas que dirigen el pensamiento del posible elector.

- En la gran mayoría de las oraciones-frase se enuncian los políticos que pertenecen a la cultura clientelista, mientras que los colombianos, que aparecen encabezando y finalizando el texto, son los directos responsables de la decisión final. Igualmente, la referencia al "Estado de opinión" sólo se hace visible en el título y al final del texto, mientras que el voto de opinión y los partidos-candidatos predominan en el discurso.

- Con respecto a la lexicalización (cómo nombra), en el discurso es común encontrar referencias a los actores políticos: partidos y movimientos, candidatos, electores e instituciones. Sin embargo, los modalizadores (cómo califica) son negativos y apocalípticos, puesto que cromatizan la política como tradicional, clientelista y sin una luz de cambio a corto plazo. Es decir, es evidente en la columna el uso de formas de nombrar y calificar de manera negativa, pues al no aparecer con claridad el nombre de algunos candidatos lo deja al conocimiento o creencia del lector-elector.

- La columnista trata de guiar la opinión de los electores mediante el uso de deónticos, tales como: "Deben escoger entre la Selección Colombia de Fajardo y la Unión Temporal de los Verdes", "Se deberán conformar", "Deberá considerarse ganadora del voto de opinión". Además, hace un paralelo entre el estado de opinión y clientelismo, y profetiza que seguirá predominando el clientelismo sobre los votos de opinión. 
- La ruta temporal que marca la autora en el discurso: futuro, pasado, presente y futuro; es consecuente con una estructura apocalíptica donde se informa sobre el hecho que está próximo a cumplirse, pero se invalida su aspecto positivo con respecto a los hechos de las elecciones del 2006 y al presente de las componendas políticas y de las pocas alternativas de opinión. Asimismo, constata el futuro negativo de las elecciones, pues las valoraciones de la columnista están basadas en a) conocimientos personales, cuando se refiere a los movimientos clientelistas de los exalcaldes de Bogotá; b) conocimiento grupal, en el momento que relata los movimientos de votos y candidatos entre los partidos; c) conocimiento institucional, cuando toma los datos de las pasadas elecciones; y $d$ ) conocimiento cultural cuando acude a saberes del común con respecto de la política tradicional y sus herencias, partidos, corrupciones, modos de proceder.

- Se advierte manipulación cuando deja sin fundamentar sus juicios frente a los candidatos que se aliaron con Antanas Mockus; mientras que las metáforas se instalan como estructuras definidas para manejar las valoraciones negativas. El uso de expresiones modalizadoras o cromatizadoras, tales como: caras ("nuevas"), congresistas ("primíparos"), caciques ("regionales"), padres ("inmolados"), abuelos ("recordados"), entre otras, aportan un juicio valorativo; luego estas expresiones son descripciones generalmente reconocidas por muchos destinatarios $\mathrm{y}$, por tanto, constituyen conocimiento compartido, pues son valoraciones que, según gocen de un mayor o menor grado de aceptación, podrán considerarse como opiniones o como actitudes políticas ampliamente compartidas, aunque estas palabras pueden ser interpretadas de manera diferente según los modelos mentales de la columnista y de los destinatarios del mensaje.

- Aunque en el artículo la columnista se impersonaliza y, por tanto, no presenta una descripción de su posición, establece una relación crítica, enjuiciadora y de denuncia contra los candidatos y las formas tradicionales de la política tradicional (parroquial). Sin embargo, apoya a la campaña de Sergio Fajardo por encima del partido de los Verdes y, de esta manera, expone el listado de candidatos independientes que integran la lista de la Selección Colombia y de la "ruta distinta" que emplea el candidato para conseguir los votos de opinión en la medida que la apropiación del discurso guarda relación con el conocimiento compartido y en ocasiones impartido en el mensaje, de tal manera que induce el significado deseado en la memoria colectiva de muchos de los destinatarios. La descripción de los actores devela los hechos y acciones de ellos, combinando el conocimiento general y el sentido común compartido por el enunciador y los destinatarios, obviamente con elementos de valoración ideológica, tales como las figuras retóricas, debido a que estas hacen parte esencial en el análisis pedagógico, pues no solo explican temáticas, sino que amplían información a través de los ejemplos, paralelos y descripciones. 


\section{Fuentes consultadas}

Bernstein, B. (2001). La estructura del discurso pedagógico. Madrid: Morata.

Bosio, I. (2011). "La divulgación de Análisis Sensorial de Vinos en soporte web. El discurso de una práctica didáctica”. Saarbrücken: Editorial Académica Española.

Capellino, L. (2009). "El contrato de lectura: un modelo de análisis de medios de comunicación gráficos”. Extraída el 12/XI/2009 desde http://linguisticasemiotica.suite101. net/article.cfm/el_contrato_de_lectura

Ciapuscio, G. y Kuguel, I. (2002). "Hacia una tipología del discurso especializado: aspectos teóricos y aplicados", pp. 37-83. En García J. y Fuentes, M. (eds.). Entre la terminología, el texto y la traducción. Extraída el 23/III/2010 desde http://www.caicyt.gov.ar/coteca/ integrantes-2/textos-de-los-integrantes/hacia-una-1.pdf/view

Lakoff, G. y Johnson, M. (1980). Metáforas de la vida cotidiana. Madrid: Cátedra.

Lawson, A. (1994). "Uso de los ciclos de aprendizaje para la enseñanza de destrezas de razonamiento científico y de sistemas conceptuales". Enseñanza de ciencias. Revista de investigación y experiencias didácticas. Vol. 12, núm. 2, pp. 165-187.

Leal Ladrón de Guevara, A. (2009). "Introducción al discurso pedagógico". Horizontes Educacionales. Vol. 14, núm. 1, pp. 51-63. Extraída el 30/VI/2014 desde http://redalyc. uaemex.mx/src/inicio/ArtPdfRed.jsp?iCve=97912444004

Lozano, J. (2007). Teoría e Investigación de la Comunicación de masas. México D. F.: Pearson Educación.

Meyer, M. (2003). "Entre la teoría, el método y la política: la ubicación de los enfoques relacionados con el ACD”, pp. 35-59. En Wodak, R. y Meyer, M. (comps.). Métodos de análisis crítico del discurso. Barcelona: Gedisa.

Silva, A. (2010, enero 30). "Estado de Opinión y clientelismo". Extraída el 30/VI/2014 desde http://www.eltiempo.com/archivo/documento/MAM-3816396

Toulmin, S. (1958). The uses of argument. Cambridge: Cambridge University Press.

Van Dijk, T.

_(2010). “Discurso, conocimiento, poder y política”. Revista de Investigación Lingüística, núm. 13, pp. 167-215.

(2008). El discurso como estructura y proceso: introducción multidisciplinaria. Barcelona: Gedisa.

_(2006). "Discurso y manipulación: discusión teórica y algunas aplicaciones". Revista Signos. Vol. 39, núm. 60, pp. 49-74. 
_(2004). "Discurso y dominación". Conferencia de en la Universidad Nacional de Colombia. Sede Bogotá. Facultad de Ciencia Humanas. Grandes Conferencias en la Facultad de Ciencias Humanas.

_(2002a). "Tipos de conocimiento en el procesamiento del discurso", pp. 41-66. En Parodi, G. (ed.). Lingüistica e interdisciplinaridad: Desafios del nuevo milenio. Valparaíso: Universidad Católica de Valparaíso.

_(2002b). "Conocimiento, elaboración del discurso y educación”. Revista Escribanía, núm. 8, pp. 5-22.

(1996). "Opiniones e ideologías en la prensa: una teoría sociocognitiva de la representación”. Voces y culturas, núm. 10, pp. 9-50. Extraída el 24/X/2009 desde http:// www.discursos.org/oldarticles/Opiniones $\% 20 \mathrm{e} \% 20$ ideolog $\%$ EDas $\% 20 \mathrm{en} \% 201 \mathrm{a} \% 20$ prensa.pdf

Vásquez, M. y Peña, J. (2013). "Manipulación, pedagogía y cultura política en la prensa colombiana". Revista Virtual Universidad Católica del Norte, núm. 38. Extraída el 30/VI/2014 desde http://revistavirtual.ucn.edu.co/index.php/RevistaUCN/article/ view/412/835 